\title{
The association of prenatal exposure to benzophenones with gestational age and offspring size at birth
}

\author{
Hakimeh Teiri ${ }^{1}$. Mohammad Reza Samaei ${ }^{1}$ (1) $\cdot$ Mansooreh Dehghani ${ }^{1} \cdot$ Abooalfazl Azhdarpoor $^{1}$. \\ Yaghoub Hajizadeh ${ }^{2} \cdot$ Farzaneh Mohammadi $^{3} \cdot$ Roya Kelishadi $^{2}$
}

Received: 3 August 2021 / Accepted: 16 November 2021 / Published online: 26 November 2021

(c) The Author(s), under exclusive licence to Springer-Verlag GmbH Germany, part of Springer Nature 2021

\begin{abstract}
In recent decades, emerging environmental pollutants such as endocrine-disrupting chemicals (EDCs) have become a particular concern. This study examined the association of maternal exposure to benzophenones as one of the EDCs with gestational age and evaluated their effects on birth outcomes including birth weight, birth length, head circumference, and Ponderal Index. We assessed 166 pregnant mothers of the PERSIAN cohort population of Isfahan, Iran, in the 1st and 3rd trimesters of pregnancy and their infants at birth. Four common benzophenones (BPs) including 2,4-dihydroxy benzophenone (BP-1), 2-hydroxy-4-methoxy benzophenone (BP-3), 4-hydroxy benzophenone (4-OH-BP), and 2,2'-dihydroxy-4-methoxy benzophenone (BP-8) were measured in maternal urine samples. The median urinary concentrations of 4-OH-BP, BP-3, BP-1, and BP-8 in the 1st trimester were 6.62, 7.5, 4.39, and $1.32 \mu \mathrm{g} / \mathrm{g}$ creatinine and those in the 3 rd trimester were 3.15, 16.98, 9.95 , and $1.04 \mu \mathrm{g} / \mathrm{g}$ creatinine, respectively. BP-3 was the predominant metabolite in both trimesters. There was a significant correlation between BP-3, BP-1, and 4-OH-BP levels $(p<0.05)$ but not BP-8. BP-1 showed a significant positive association with gestational age (GA) in all infants in the 1st trimester, but a negative association was observed between BP-3 and BP-1 levels and GA in girls. Classification of infants' birth weight for different GAs represented that the majority of them were appropriate for GA. However, boys' weights were heavier than girls. Also, birth outcomes of preterm ( $<37$ weeks $)$ infants were noticeably lower than term infants (37-42 weeks). This study demonstrated that benzophenone derivatives especially BP-3 can affect the duration of pregnancy and consequently fetal growth in the early and late stages of pregnancy. This is more pronounced in girls; however, more investigations in a different population are needed to prove the results. Therefore, the application of these compounds as a UV protector requires precise regulation to reduce exposure, especially in pregnant women.
\end{abstract}

Keywords Benzophenones $\cdot$ Birth outcomes $\cdot$ Exposure $\cdot$ Gestational age $\cdot$ Pregnancy $\cdot$ Trimester

Responsible Editor: Lotfi Aleya.

Mohammad Reza Samaei

mrsamaei@sums.ac.ir

Roya Kelishadi

kelishadi@med.mui.ac.ir

1 Department of Environmental Health Engineering, School of Health, Shiraz University of Medical Sciences, Shiraz, Iran

2 Environment Research Center, Research Institute for Primordial Prevention of Non-Communicable Diseases, Isfahan University of Medical Sciences, Isfahan, Iran

3 Department of Environmental Health Engineering, Faculty of Health, Isfahan University of Medical Sciences, Isfahan, Iran

\section{Introduction}

Benzophenones (BPs) are one of the emerging environmental pollutants and are listed in the group of endocrinedisrupting chemicals (EDCs) which can interfere with the function of human and animal hormones (Yang et al. 2013; Darbre 2019). These compounds are used in personal care products, cosmetics, sunglasses, plastic packaging, and sunscreens as UV protectors (Ghazipura et al. 2017). BPs may naturally be present in some foods such as grapes, mountain papaya, and black tea (Heurung et al. 2014). They are also used as flavoring compounds, and odor stabilizers, in the printing industry, and in sleeping pills (Alamri et al. 2021). The human absorption routes of benzophenones are inhalation, skin absorption, and ingestion. Recent studies have 
reported the presence of BPs in urine, blood, and breast milk (Delgado et al. 2017; Krause et al. 2018). As urine is the major route of excretion of EDC metabolites, measuring the concentration of BP metabolites in the urine can indicate a general exposure to BPs (Kawaguchi et al. 2009).

The main effects of BPs and their derivatives include carcinogenicity, dysfunction of endocrine hormones, eczema, toxicity for fetal growth and reproduction, adverse effects on human organs such as the liver, and disruption of the natural ecosystem (Kerdivel et al. 2013; Li et al. 2014). According to USEPA and IARC, benzophenones are potential carcinogens for humans (group B), and there is sufficient evidence from various studies to show that they are carcinogenic to animals (Mattison et al. 1990; Rhodes et al. 2007; Anonymous 2020; Mistry et al. 2021). There are several benzophenones with diverse structures and biological activities. Among them, 2,4-dihydroxy benzophenone (BP1), 2-hydroxy-4-methoxy benzophenone (BP-3), 4-hydroxy benzophenone (4-OH-BP), and 2,2'-dihydroxy-4-methoxy benzophenone (BP-8) are commonly detected in biological samples. BP-8 is a minor metabolite of BP-3 and BP-1 and 4-OH-BP are phase-I reaction metabolites of BP-3 (Suzuki et al. 2005). BP-3 and 4-OH-BP as derivatives of $\mathrm{BPs}$, with strong estrogenic activity, can cause breast cancer and endometriosis, pass through the skin, and accumulate in the blood, kidneys, and liver (Kunisue et al. 2012; Kim and Choi 2014; Smarr et al. 2016; Karthikraj and Kannan 2018; Barone et al. 2019).

Due to the risks associated with the widespread use of BPs containing products, researchers have paid more attention to these chemicals over the last decades (Kim and Choi 2014). The exposure level of BPs in different countries may be affected by various factors such as population cultures and their behaviors of using BP content products and the existence of strict rules to limit the use of BPs in different industries (Dodson et al. 2020). According to recent studies, BP derivatives can penetrate in a recognizable level from the placenta to human amniotic fluid and fetal blood circulation affecting fetal growth because of their highly toxic potential (Krause et al. 2018). BP derivatives can affect fetus growth indirectly by interfering duration of pregnancy or directly by the mechanism of disrupting endocrine hormones. They bind to human estrogen receptor $\alpha$ (hER $\alpha$ ) and $\beta$ (hER $\beta$ ) and interfere with the normal process of offspring growth (Kunz et al. 2006; Molina-Molina et al. 2008). These make pregnant women and their offspring one of the most vulnerable groups in exposure to these pollutants all over the world (Long et al. 2019). Although correlations of exposure to other pollutants such as heavy metals (Wai et al. 2017; Moradnia et al. 2021), parabens (Hajizadeh et al. 2021), bisphenol a (Wan et al. 2018; Zhou et al. 2019), and phthalate (Santos et al. 2021) with offspring birth outcomes have been reported, studies on the effects of BPs on pregnant women and their infants are not conclusive. However, the available evidence has shown that BPs by disrupting hormonal activities and inflammatory responses can impact the duration of pregnancy (Wolff et al. 2008; Tang et al. 2013; Aker et al. $2016,2019)$. They may interfere with the normal growth process, development of the reproductive system, and hormonal balance of the fetus (Nakamura et al. 2015; Balázs et al. 2016).

Birth size and gestational age can be good indicators of an infant's health. Therefore, investigation of the factors affecting the duration of pregnancy and its impacts on infant size is very essential. Infants born earlier than 37 weeks are considered premature and the pregnancy is called preterm birth (PTB). Such babies usually have many problems in the early and late years of their life. PTB or birth weight less than $2.5 \mathrm{~kg}$ can lead to consequences such as infant death, increased neurological disorders, respiratory system, visual and hearing impairment, and cerebral palsy (Blencowe et al. 2013; Luu et al. 2016). On the other hand, late birth over 40 weeks, in addition to increasing the risk of stillbirth or adverse birth conditions for the baby, has serious risks for the mother including increased cesarean delivery, perineal lacerations, and postpartum hemorrhage, likely due to the large size of the baby (Galal et al. 2012; Aker et al. 2019).

Although some studies have not achieved a consistent association of $\mathrm{BP}$ exposure during pregnancy with preterm delivery (Mustieles et al. 2020), others have shown the effect of various BP derivatives on decrease or increase of pregnancy length (Aker et al. 2016, 2018, 2019; Long et al. 2019). Some studies demonstrated that exposure to BP-3, one of the most commonly used ingredients in sunscreens, during pregnancy reduces gestational age, increases neonatal head circumference by up to $0.3 \mathrm{~cm}$, and increases the birth weight of male infants and, conversely, decreases the birth weight of female infants (Wolff et al. 2008; Philippat et al. 2012, 2019; Tang et al. 2013). A study in China showed that each logarithmic unit increase of BP-1 and 4-OH-BP concentrations in urine in the 1 st trimester of pregnancy resulted in a $0.6 \mathrm{~mm}$ and $0.8 \mathrm{~mm}$ decrease in infants' birth height, respectively. Additionally, BP-1 and BP-3 were also associated with weight loss at birth, which was more pronounced in female infants (Long et al. 2019).

Considering the adverse health effects of BPs on pregnant women and their infants, and the presence of these chemicals in a wide range of substances, in this study, we evaluated the urinary level of the four most common and high estrogenic activity BPs (BP-1, 4-OH-BP, BP-8, BP-3), during the 1st and 3rd trimesters as the most critical period of pregnancy. We also assessed the correlation between urinary levels of BP derivatives and gestational age, as well as the impacts of gestational age on infants' birth weight and length, head circumference, and Ponderal Index. To the best of our knowledge, this study was conducted for the first time in Iran, 
as one of the high cosmetic consumption regions (Hosseini et al. 2014). The findings of this study can provide information on BP exposure level, and outline the possible association of BP-3, BP-1, BP-8, and 4-OH-BP with gestational age and their consequences on offspring size. These findings differentiate the importance of limiting the use of products containing these compounds among vulnerable groups such as pregnant women.

\section{Materials and methods}

\section{Study population}

The study population was selected from the participants in the PERSIAN (Prospective Epidemiological Research Studies in IRAN) Birth Cohort (Sakhvidi et al. 2021; Hajizadeh et al. 2021). This cohort study evaluates the associations of socio-economic characteristics, lifestyle, diet, environmental exposures, and epigenetic factors with pregnancy outcomes, mother and child mental and physical health and well-being, child neurodevelopment, and risk factors for the establishment of chronic diseases. Participants were selected from pregnant women living in different areas of Isfahan, one of the industrial metropolises of Iran. Inclusion criteria of the study were being in the 1st trimester of pregnancy, living at the same address for more than 1 year, and not having any chronic and underlying diseases. Exclusion criteria were having any hormone-related illnesses and hormone therapy, multiple or twin gestations, and occupations that cause exposure to these compounds such as working in hairdressers, cosmetics manufacturing, and packaging and printing industries. In this study, 170 eligible pregnant women of the PERSIAN cohort participants were enrolled, but four of them who had a miscarriage before sampling time were excluded. First of all, the objectives of the study and the required information in the questionnaire as well as voluntarily participating in the study were explained to the participants in the first visit of pregnancy checkup, and then consent form was signed by the individuals. Characteristics of the study population (demographic, socio-economic, and lifestyle information) were recorded via a face-to-face interview by trained experts. The pre-pregnancy weight of these women was recorded based on their statements, but their weight was measured at the 1 st- and 3rd-trimester visits, as well as before delivery in the hospital with standard and calibrated instruments. Due to the COVID-19 outbreak and lockdown program, only 87 participants attended the 3rd-trimester sampling. However, the birth outcomes of 162 infants of mothers during delivery were measured and recorded by the experienced nurses of the hospital with standard and calibrated devices. The protocol and method of the present study were approved by the Persian Cohort Ethics Committee (IR.MUI.REC.1394.1.354) (Sakhvidi et al. 2021).

\section{Chemicals and analytical reagents}

The chemicals used in this study were analytical grade of four benzophenone derivatives including 2,4-dihydroxy benzophenone (BP-1), 2-hydroxy-4-methoxy benzophenone (BP-3), 2,2'-dihydroxy-4-methoxy benzophenone (BP-8), and 4-hydroxy benzophenone (4-OH-BP), and $\beta$-glucuronidase/sulfatase enzyme (Helix pomatia type HP-2) and N-methyl-N-(trimethylsilyl) trifluoroacetamide (MSTFA) as a derivatizing agent were purchased from Sigma-Aldrich Co. (St. Louis, MO, USA). GC grade extraction and dispersant solvents such as acetone, methanol, and trichloromethane were provided from Merck Company (Darmstadt, Germany).

\section{Sample collection, extraction, and analytical methods}

Before sampling, the participants were informed to have fasted and do not change their routine life pattern until sample delivery. Spot urine samples were collected in the early morning by referring them to the designated health centers. Participants delivered their urine samples two times during the routine pregnancy visits, one within the 1st and the other within the 3 rd trimester of pregnancy. The 1 st- and 3 rd-trimester samples were taken on average in the 12th (10-14) and 34th weeks (32-36) of pregnancy, respectively. The samples were collected in polypropylene containers and divided into two parts; one part was transferred to the medical laboratory for creatinine test and the other part was stored at $-20^{\circ} \mathrm{C}$ until the experiments were performed. The creatinine of the urine samples was analyzed according to the Jaffe method with Hitachi 704 auto-analyzer. GC, Agilent (USA) model 7890, equipped with MS, Agilent model $5975 \mathrm{Split} /$ Splitless input with a quadrupole mass spectrometer, was used for the quantification of the metabolites.

For determination of all free and combined available BP-1, 4-OH-BP, BP-8, and BP-3 compounds in the urine sample, $10 \mu \mathrm{L}$ beta-glucuronidase/arylsulfatase enzyme solution was added to each sample, rapidly mixed, then incubated at $37^{\circ} \mathrm{C}$ for $24 \mathrm{~h}$ to complete the enzymatic digestion of the mixture. Afterwards, $0.1 \mathrm{~g}$ of sodium chloride was added to the sample and placed in an ultrasonic bath at $40{ }^{\circ} \mathrm{C}$ for $10 \mathrm{~min}$. The dispersive liquid-liquid microextraction (DLLME) method was utilized to extract the BP metabolites from the urine samples. This technique is based on a tertiary solvent system that has more advantages such as simplicity, speed, low cost, high concentration factor, and high recovery (Fernández et al. 2021). The sample extraction was performed by pipetting $3-5 \mathrm{ml}$ of urine sample 
into a 2-ml falcon and adding $100 \mu \mathrm{L}$ ammonium acetate $(\mathrm{pH}=6.8)$. For DLLME extraction, $500 \mu \mathrm{L}$ acetone and $100 \mu \mathrm{L}$ trichloromethane were combined in a vial and the mixture was immediately added to the urine sample in a falcon tube to form a cloudy state. The cloudy solution was centrifuged at $5000 \mathrm{rpm}$ for $5 \mathrm{~min}$. Then, the organic phase formed at the bottom of the falcon tube was removed using a microliter syringe and dried with a gentle blow-up by nitrogen gas. Twenty microliters of MSTFA was added to the dried residue in the falcon tube as a derivatizing agent and centrifuged to mix completely. Finally, $1 \mu \mathrm{L}$ of the obtained solution was injected into the GC/MS to analyze the target compounds (Campo et al. 2008; Amin et al. 2017).

Stock solutions of 4-OH-BP, BP-3, BP-1, and BP-8 were made in methanol and kept in dark containers at $-4{ }^{\circ} \mathrm{C}$ until use. Working standards were prepared daily by diluting the stock solution in deionized water. To increase the sensitivity of the instrument and the accuracy of analysis, selected ion monitoring (SIM) mode was used to identify each metabolite. In this case, instead of measuring the entire $\mathrm{m} / \mathrm{z}$, which covers a wide range, only the number of $\mathrm{m} / \mathrm{z}$ that has the highest frequency and is specified by the user is identified. In this study, the highest frequency for 4-OH-BP, BP-3, BP-1, and BP-8, including 193, 227, 285, and $343 \mathrm{~m} / \mathrm{z}$, was selected, respectively. Helium gas with $99.999 \%$ purity and flux of $1 \mathrm{ml} / \mathrm{min}$ was used continuously as a carrier gas. To obtain the best separation and distinguish between the chromatogram peaks, different temperature programs for the column and carrier gas inlet velocities were used. The initial column oven temperature for metabolites separation was $90{ }^{\circ} \mathrm{C}$ for $2 \mathrm{~min}$, then increased to $290{ }^{\circ} \mathrm{C}$ with a temperature ramp of $8{ }^{\circ} \mathrm{C}$ per minute, and kept at this temperature for $5 \mathrm{~min}$. The injection mode was Splitless and the transfer line temperature was kept at $290{ }^{\circ} \mathrm{C}$ (Campo et al. 2008; Amin et al. 2017). To create calibration curves, the synthetic benzophenone-free urine samples (which is regular urine created in a laboratory to mimic that of clean human urine) were spiked with different concentrations $(0-100 \mu \mathrm{g} / \mathrm{L})$ of the four benzophenone metabolites. Quality control samples, prepared by spiking a known amount of BP metabolite solution into synthetic urine to achieve the target concentration, and blank samples (synthetic urine without any BP metabolites) were used to evaluate the accuracy of analytical methods. The recovery percentage for the studied metabolites was $86.67 \%$ on average, and LOD (limit of detection) for 4-OH-BP, BP-3, BP-1, and BP-8 was 0.048, 0.045, 0.055, and $0.04 \mu \mathrm{g} / \mathrm{L}$, respectively.

\section{Gestational age estimation and birth outcomes}

Gestational age was calculated based on the last menstrual cycle date reported by the mother's or using the first ultrasound documents available in the mother's clinical file
(Wegienka and Baird 2005). Anthropometric indicators of infants including weight, height, and head circumference were measured at birth by experienced hospital nurses. Infants' length was measured in a supine position with straight knees from crown to heel. Head circumference was measured from the largest diameter of the head through the back of the head and above the nasal septum (glabella and occiput) with a non-elastic tape meter. At the time of weighing, the babies were completely naked. Neonatal Apgar score was calculated by scoring infants heart rate, respiratory effort, muscle tone, skin color, and reflex irritability from 1 to10 in the first and fifth minutes after being born. To evaluate the pattern of fetal growth in small- or large-forgestational age (SGA or LGA), the Rohrer's Ponderal Index (PI), also known as Corpulence Index (CI), was calculated using the following formula (Chang et al. 2019):

Ponderal Index $=\frac{100 \times \text { body weight }(\mathrm{g})}{\text { body length }(\mathrm{cm})^{3}}$

\section{Statistical analysis}

Descriptive statistics and frequencies were produced for the characteristics of the study population, urinary metabolites of BPs in 1st and 3rd trimester of pregnancy, gestational age, birth outcomes, and correlation maps of BPs in specific sex of offsprings. The Mann-Whitney $U$ test is used to compare differences between two independent groups when the variables are either ordinal or continuous, but not normally distributed. So, in this study, urinary metabolites of benzophenones in the 1st and 3rd trimester of pregnancy were compared using the Mann-Whitney $U$ test. Correlation between urinary levels of the metabolites in the 1st and 3rd trimester of pregnancy was tested using the Spearman rank correlation coefficient. The linear regression models were also used to test the association between the metabolites of benzophenones in the 1st and 3rd trimesters with gestational age. Moreover, the concentrations of the metabolites less than the LOD were assigned by the value of LOD divided by the square root of 2 . Statistical analyses were carried out using SPSS software (SPSS Inc., Chicago, IL) version 26 based on two-tailed tests, and statistical significance was set at $p$ value $<0.05$. Correlation maps and hierarchical clustering were plotted using RStudio software version 1.3.959.

\section{Results}

The key characteristics of mothers and infants involved in the study are represented in Table 1 . The mean pregnancy age was $29.94 \pm 5.49$ (range 17-43) years, most of whom (33.95\%) were between 30 and 34 years old. The average 
Table 1 Key characteristic of pregnant women and their infants

\begin{tabular}{|c|c|c|}
\hline \multicolumn{2}{|l|}{ Maternal characteristics } & \multirow{2}{*}{$\frac{N(\%) \text { or mean } \pm \mathrm{SD}}{29.94 \pm 5.49}$} \\
\hline Maternal mean age (year) & & \\
\hline \multirow[t]{4}{*}{ Maternal age (year) } & $<25$ & $30(18.52)$ \\
\hline & $25-29$ & $44(27.16)$ \\
\hline & $30-34$ & $55(33.95)$ \\
\hline & $\geq 35$ & $33(20.37)$ \\
\hline \multirow[t]{4}{*}{ Pre-pregnancy BMI $\left(\mathrm{kg} / \mathrm{m}^{2}\right)$} & $<18.5$ & $14(8.64)$ \\
\hline & $18.5-23.9$ & $61(37.65)$ \\
\hline & $24-29.9$ & $71(43.83)$ \\
\hline & $\geq 30$ & $16(9.88)$ \\
\hline \multirow[t]{4}{*}{ BMI before delivery $\left(\mathrm{kg} / \mathrm{m}^{2}\right)$} & $<18.5$ & 0 \\
\hline & $18.5-23.9$ & $12(8)$ \\
\hline & $24-29.9$ & $64(42.67)$ \\
\hline & $\geq 30$ & $74(49.33)$ \\
\hline Pregnancy weight gain (kg) & & $13.52 \pm 6.22$ \\
\hline \multirow[t]{3}{*}{ Education } & $\leq$ Diploma & $100(61.73)$ \\
\hline & undergraduate & $55(33.95)$ \\
\hline & post graduate & $7(4.32)$ \\
\hline \multirow[t]{3}{*}{ Income } & Low & $37(23)$ \\
\hline & Moderate & $117(72.70)$ \\
\hline & High & $7(4.30)$ \\
\hline \multirow[t]{2}{*}{ Gestational diabetes } & Yes & $10(10.53)$ \\
\hline & No & 85 (89.47) \\
\hline \multirow[t]{2}{*}{ Pregnancy blood pressure } & Yes & $3(3.16)$ \\
\hline & No & $92(96.84)$ \\
\hline \multirow{2}{*}{$\begin{array}{l}\text { Passive smoking during 1st } \\
\text { trimester }\end{array}$} & Yes & $39(24.68)$ \\
\hline & No & $119(75.32)$ \\
\hline \multirow{2}{*}{$\begin{array}{l}\text { Passive smoking during 3rd } \\
\text { trimester }\end{array}$} & Yes & $18(22.22)$ \\
\hline & No & $63(77.78)$ \\
\hline \multirow[t]{2}{*}{ Pregnancy supplement } & Yes & $155(97.48)$ \\
\hline & No & $4(2.52)$ \\
\hline Infant characteristics & & $N(\%)$ or mean $\pm \mathrm{SD}$ \\
\hline \multirow[t]{2}{*}{ Sex } & Male & $89(56.69)$ \\
\hline & Female & $68(43.31)$ \\
\hline Birth weight (g) & & $2961.68 \pm 832.6$ \\
\hline Birth length (cm) & & $47.25 \pm 11.77$ \\
\hline Head circumference $(\mathrm{cm})$ & & $32.37 \pm 8.44$ \\
\hline Gestational age (week) & & $38.71 \pm 1.71$ \\
\hline Apgar & & $9.89 \pm 0.33$ \\
\hline Ponderal index $\left(\mathrm{g} / \mathrm{cm}^{3}\right)$ & & $2.51 \pm 0.34$ \\
\hline
\end{tabular}

gestational age was obtained $38.71 \pm 1.71$ weeks. Among mothers, $37.65 \%$ had normal BMI before pregnancy, but $18.52 \%$ of them were abnormally lean or obese. The mean weight gain during pregnancy was $13.52 \pm 6.22 \mathrm{~kg}$; however, there was an increase of $40.55 \%$ in the obese group during pregnancy. The education level of $61.73 \%$ of mothers was primary and diploma, and a limited number of them (4.32\%), were university graduates. According to Iranian basic salary, $72.70 \%$ of the study population had moderate monthly income. During pregnancy, $13.69 \%$ of the mothers were diagnosed with pregnancy diabetes and hypertension. Also, $46.9 \%$ of them were exposed to secondhand smoke.

The detection rates of BP-3 and BP-1 both in the 1st and 3rd trimesters were $100 \%$. But the detection rates for $4-\mathrm{OH}-$ BP and BP- 8 were $98 \%$ and $95 \%$ in the 1st trimester, and $82 \%$ and $89 \%$ in the 3rd trimester, respectively. The results of mothers' urinary BP levels in the 1st and 3rd trimester, volume-based $(\mu \mathrm{g} / \mathrm{L})$ and adjusted with creatinine $(\mu \mathrm{g} / \mathrm{g} \mathrm{Cr})$, are shown in Table 2. The median concentration of metabolites in both trimesters showed significant differences except for creatinine-adjusted BP-3 and BP-1. However, these two metabolites demonstrated higher median concentration in the 3rd trimester compared to the 1st trimester. Also, BP-3 had the highest concentration among the other metabolites in both the 1st and 3rd trimesters.

For evaluation of the correlation between the BP metabolites in each trimester, heat maps were created for the creatinine-adjusted concentrations which are represented in Figs.1, 2, and 3. Figure 1 illustrates the correlation within the metabolites in the 1st and 3rd trimesters in the total studied infants. These metabolites in the 1st and 3rd trimesters of pregnancy were positively correlated with a large and significant coefficient, which means that with increasing one of the metabolite's levels, the others were also increased. According to tree classification and correlation coefficients, BP-1 and BP-3 had the highest correlation with each other followed by 4-OH-BP in both trimesters of pregnancy. BP-8 had the lowest correlation with the other metabolites, but this correlation was significant. Although in the 3 rd trimester the conditions were similar to those in the 1st trimester, the correlation between BP-8 and 4-OH-BP was not significant. Also, no significant correlation was observed between the concentrations of metabolites in the 1st and 3rd trimesters.

Further stratification by infant sex showed that in girls, in the 1st trimester, the concentration of the metabolites had a significantly positive correlation with each other, while in the 3rd trimester only BP-1 and BP-3 showed a significant association, but this was not observed within the other metabolites (Fig. 2). In the 1st trimester, BP-1 and BP-3 had the highest correlation according to tree classification and correlation coefficients, and 4-OH-BP showed the highest correlation with these metabolites, but BP-8 had less significant correlation with the other variables. However, no significant correlation was observed between the levels of metabolites in the 1st and 3rd trimesters.

Figure 3 illustrated that correlation between the metabolites in each trimester was more obvious in boys. The correlation of pollutants in male infants in both trimesters is quite similar to the overall results of the total infants. Also in contrast to Figs. 1 and 2, a significant correlation was observed in male infants between the concentrations of BP-1, BP-3, and 4-OH-BP in the 1st trimester with their 
Table 2 Distribution of urinary metabolites of benzophenones ( $\mu \mathrm{g} / \mathrm{g}$ creatinine) in $1 \mathrm{st}(N=166)$ and 3rd $(N=87)$ trimesters of pregnancy

\begin{tabular}{|c|c|c|c|c|c|c|c|c|c|c|c|c|}
\hline \multirow[t]{2}{*}{ Trimester } & \multirow{2}{*}{ Metabolite } & \multirow[t]{2}{*}{ Mean } & \multirow[t]{2}{*}{$\mathrm{SD}$} & \multirow{2}{*}{ Median } & \multirow[t]{2}{*}{ Min } & \multicolumn{5}{|c|}{ Percentiles } & \multirow{2}{*}{ Max } & \multirow{2}{*}{$p$ value ( $t$-test) } \\
\hline & & & & & & 5 & 25 & 50 & 75 & 95 & & \\
\hline 1 st & 4-OH-BP & 15.01 & 35.42 & 6.62 & $<$ LOD & 0.28 & 2.24 & 6.62 & 13.43 & 51.31 & 377.78 & 0 \\
\hline $3 \mathrm{rd}$ & 4-OH-BP & 3.52 & 3.15 & 3.15 & 0.08 & 0.13 & 1.13 & 3.15 & 5.31 & 9.36 & 9.6 & \\
\hline 1 st & BP-3 & 14.65 & 22.31 & 7.5 & 0.41 & 1.22 & 3.84 & 7.5 & 17.53 & 58.04 & 205.75 & 0.24 \\
\hline $3 \mathrm{rd}$ & BP-3 & 19.66 & 16.98 & 16.98 & 4.73 & 5.25 & 10.99 & 16.98 & 26.06 & 45.65 & 49.47 & \\
\hline $1 \mathrm{st}$ & BP-1 & 9.66 & 17.43 & 4.39 & 0.31 & 0.67 & 2.22 & 4.39 & 10.24 & 39.6 & 151.77 & 0.6 \\
\hline $3 \mathrm{rd}$ & BP-1 & 11.37 & 9.95 & 9.95 & 2.86 & 3.19 & 6.44 & 9.95 & 15.02 & 26.02 & 27.95 & \\
\hline 1 st & BP-8 & 2.53 & 3.93 & 1.32 & $<$ LOD & 0.13 & 0.58 & 1.32 & 2.3 & 11.6 & 23.12 & 0 \\
\hline $3 \mathrm{rd}$ & BP-8 & 1.2 & 1.04 & 1.04 & 0.04 & 0.28 & 0.76 & 1.04 & 1.56 & 2.86 & 2.95 & \\
\hline
\end{tabular}

4-OH-BP 4-hydroxy benzophenone, BP-3 2-hydroxy-4-methoxy benzophenone, $B P-1$ 2,4-dihydroxy benzophenone, $B P-8$ 2,2'-dihydroxy4-methoxy benzophenone

concentrations in the 3 rd trimester. This was indicating that the pregnant women with male neonates were more affected by these contaminants. Meanwhile, mothers with girl neonates represented a lower association among these pollutants in each trimester and the relationship between the 1st and 3rd trimesters.

Examination of the relationship between urinary BP derivatives and gestational age (GA) adjusted for maternal age, pre-pregnancy BMI, weight gain during pregnancy, passive smoking, household monthly income, and education is represented in Table 3. In the 1st trimester of pregnancy, there was a significant positive association between BP-1 and GA with $p$ value $<0.019$ in all neonates. However, stratification by gender demonstrated a strong negative correlation among GA and BP-3 as well as BP-1 in girls with $p$ value $<0.034$ in the 1 st trimester, whereas in boys, only
Fig. 1 Correlation maps and Hierarchical clustering between the different parameters. Cell colors from light brown to dark brown indicate minimum to maximum Spearman correlation coefficients, respectively. Asterisks indicate significant correlations $(* p<0.05 ; * *<<0.01)$. $\mathrm{f}$ stands for 1 st and $t$ sands for $3 \mathrm{rd}$ trimester

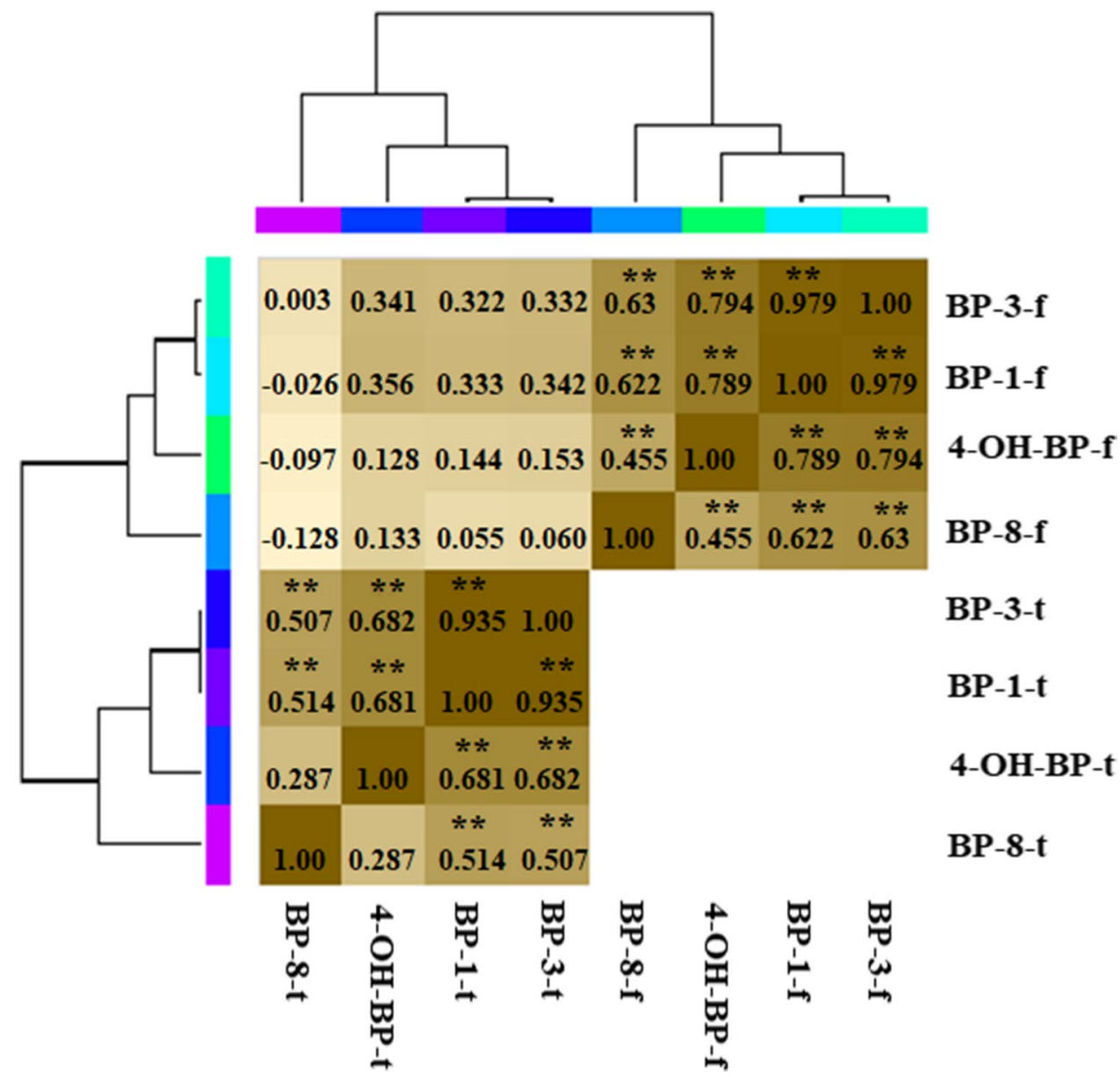


Fig. 2 Correlation maps and Hierarchical clustering between the different parameters in girls. Cell colors from light to dark purple indicate minimum to maximum Spearman correlation coefficients, respectively. Asterisks indicate significant correlations $(* p<0.05 ; * * p<0.01)$. $\mathrm{f}$ stands for 1 st and $t$ sands for $3 r d$ trimester

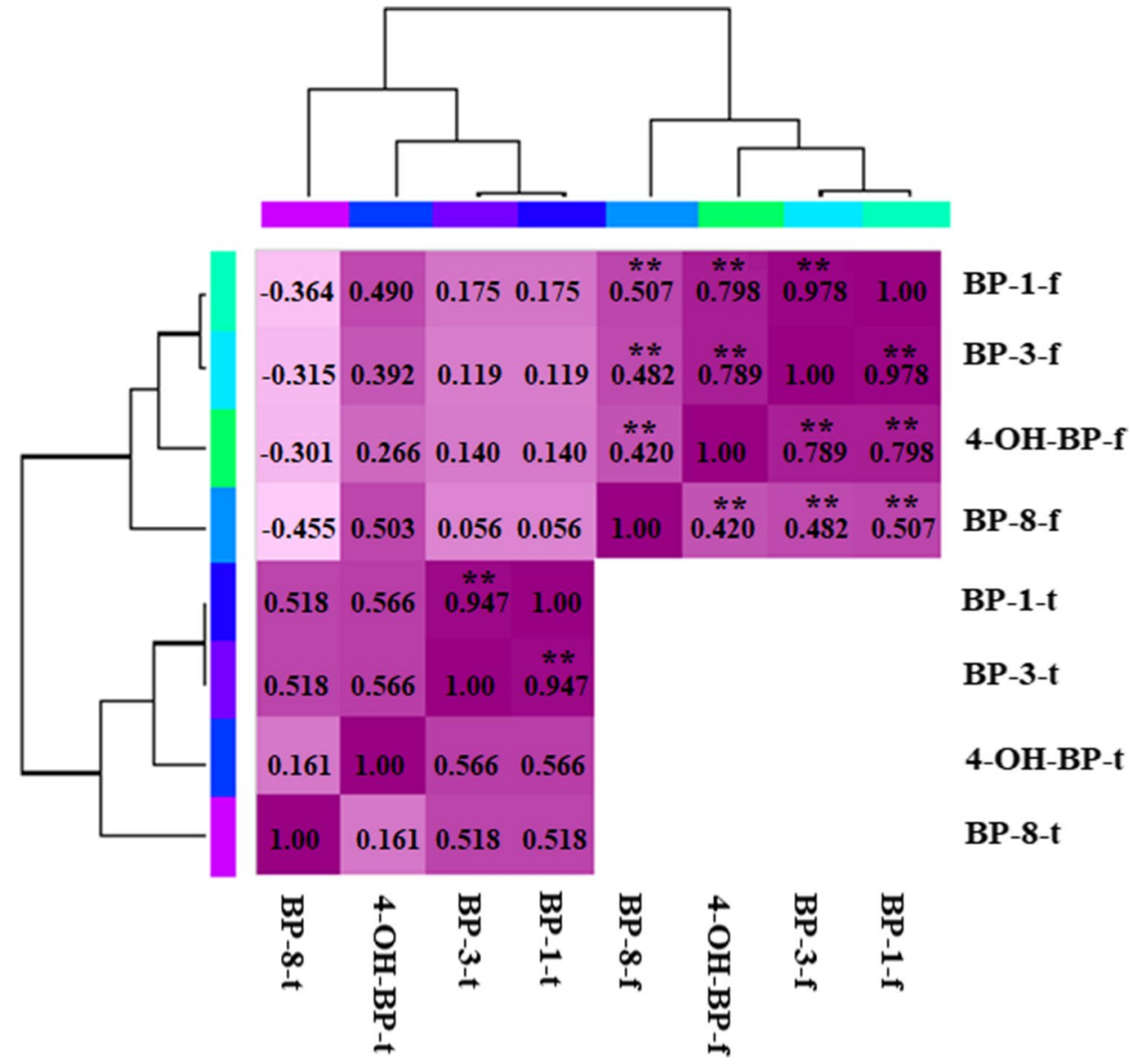

BP-8 represented association with GA in the 1 st trimester with $p$ value $<0.049$.

The influence of pregnancy duration on newborn birth size was further investigated. Characteristics of the infant's birth weight and classification as small, appropriate, or large for gestational age are represented in Table 4. Infants with a birth weight under $2315 \mathrm{~g}$ (10th percentile) were propounded small for gestational age (SGA), those with a weight above $3664 \mathrm{~g}$ (90th percentile) were considered large for gestational age (LGA), and those with a weight between 2315 and $3664 \mathrm{~g}$ were accounted for appropriate for gestational age (AGA). According to Table $4,78.3 \%$ of the newborn infants were in the AGA group. Sex-specific classification showed that the median birth weight of male infants was $3250 \mathrm{~g}$ where $78.7 \%$ of them were in the AGA group followed by $11.2 \%$ in LGA and $9 \%$ in the SGA group. Although median weight in girls was less than boys, the percentage of girls with AGA $(80.9 \%)$ was more than that of boys. Table 5 represents the characteristics of GA and the classification of delivery terms among the studied mother-infant subjects. The median GA was 39 weeks with the range of 32-43 weeks. $89.75 \%$ of mothers had term delivery between 37 and 42 weeks, $8.4 \%$ had preterm delivery (earlier than
37 weeks), and only $1.8 \%$ of them had post-term delivery (later than 42 weeks).

Statistical data of infants' birth outcomes, including weight, height, head circumference, and Ponderal Index classified versus different gestational ages, are shown in Table 6. The mean weight of infants with preterm and post-term birth was $2640 \mathrm{~g}(95 \% \mathrm{CI}, 2326-2745)$ and $3175 \mathrm{~g}(95 \% \mathrm{CI}$, 3107-3242), respectively. Due to the small number of postterm birth groups (just 3 birth), some parameters seemed to be unreasonable and unreliable and were not presented in the table. The difference in the newborns' height was more pronounced, with normal-term birth groups being $3.895 \mathrm{~cm}$ taller than premature infants. Infants' head circumference varied from a minimum of $32 \mathrm{~cm}$ to a maximum of $36 \mathrm{~cm}$ in the three GA groups. PI of preterm and term birth infants did not show a noticeable difference.

\section{Discussion}

In this study, the most common benzophenone derivatives in the urine samples of Iranian pregnant women were monitored in the 1st and 3rd trimesters of their pregnancy and their association with gestational age was investigated. 
Fig. 3 Correlation maps and Hierarchical clustering between the different parameters in boys. Cell colors from light to dark green indicate minimum to maximum Spearman correlation coefficients, respectively. Asterisks indicate significant correlations $(* p<0.05 ; * *<<0.01) . \mathrm{f}$ stands for 1 st and t sands for 3 rd trimester

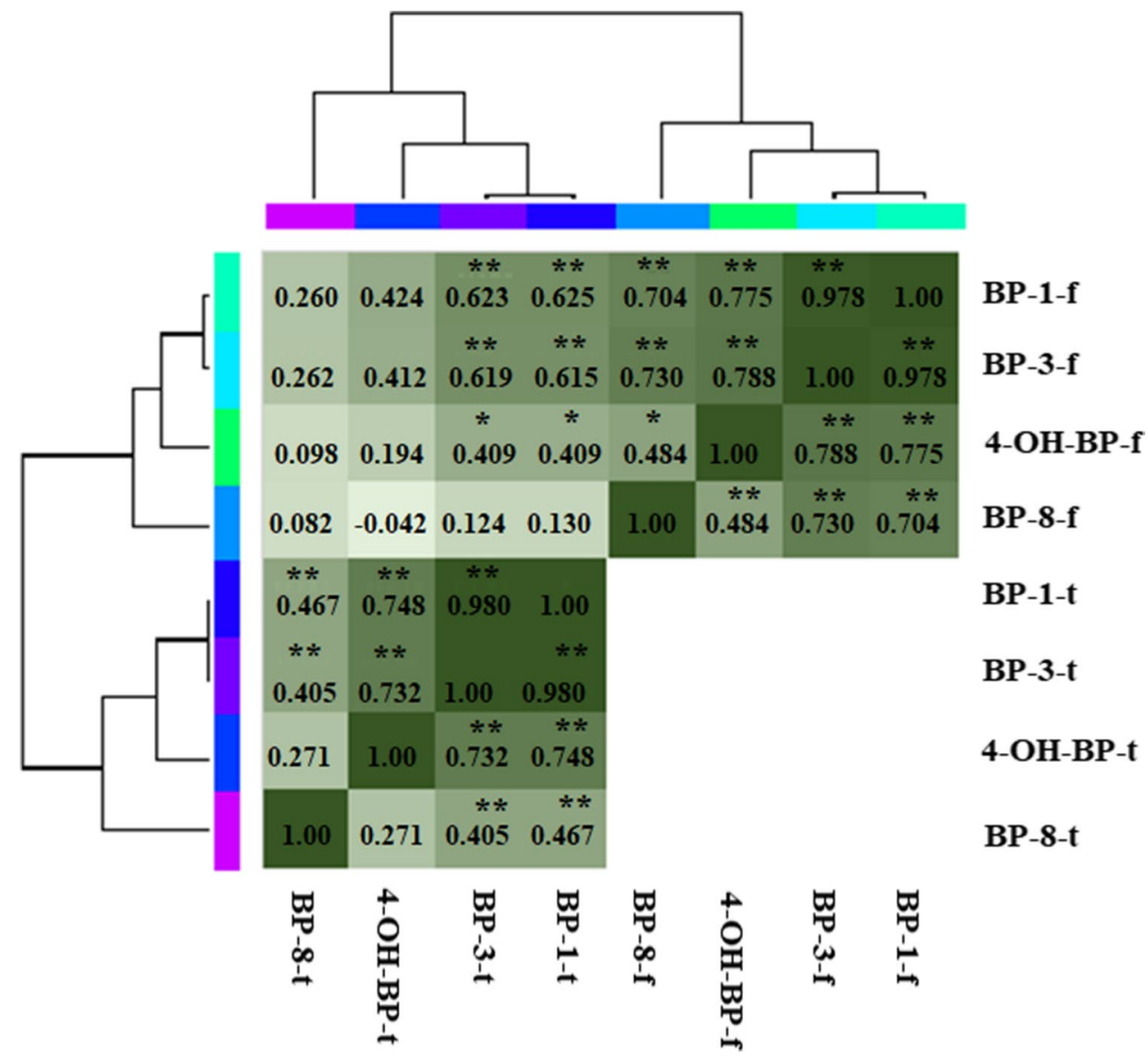

Also, the effects of pregnancy duration on a newborn's size were evaluated. Despite the huge use of substances containing benzophenone compounds in Iran and their possible health risks, especially for pregnant women and their infants, by now, no human studies have been performed on benzophenone biomonitoring and their adverse health outcomes in this country. Various studies have proven that benzophenone derivatives such as 4-OHBP, BP-3, BP-1, and BP-8 due to having low molecular weight can easily transfer from the placenta barrier to the fetus (Tang et al. 2013). Comparison of these metabolite concentrations in cord and pregnancy serum demonstrated that the fetus exposure to these contaminants is much higher than the mother herself, which can have adverse effects on fetal normal growth, birth outcomes, and gestational duration (Long et al. 2019; Song et al. 2020). Also, excretion and removal of phenolic compounds from the fetus are slower than placenta, because the UDPGT isozyme (uridine diphosphate-glucuronosyltransferase), responsible for the elimination of most xenobiotic, is activated after birth (Coughtrie et al. 1988; Takahashi and Oishi 2000). Therefore, to prevent irreversible complications of these chemical compounds in the infant's early and later stages of life, their exposure level should be under control.
A high detection rate of the studied BP derivatives in the mothers' urine in this research was achieved, compared to other studies conducted in China (Jiang et al. 2019; Chen et al. 2021), which could be attributed to the high sensitivity of our analytical method and reaching very low LOD for these metabolites. Even in many studies of maternal exposure to BP derivatives, the concentration of BP-8 has not been evaluated, or its detection rate was very low, around 13\% (Song et al. 2020) and 2\% (Zhao et al. 2017). A high median concentration of BP-8 in the 1st and 3rd trimesters of pregnancy $(1.1-1.9 \mu \mathrm{g} / \mathrm{L})$ in the present study was detected compared to the concentration $<0.001 \mu \mathrm{g} / \mathrm{L}$ in the mentioned studies. However, the detection rate of all metabolites in our study was in close agreement with that reported in a study that assessed urinary levels of BPs in Chinese and American adults and children with a detection rate of $100 \%$ for BP-3 and BP-1, and 93\% and 60\% for 4-OH-BP and BP-8 respectively (Wang and Kannan 2013).

BP-3 with the highest concentration was predominant among other metabolites in the 1 st and 3rd trimesters, which is in line with the findings of other studies (Gao et al. 2015; Zhao et al. 2017; Long et al. 2019). This is reasonable because the study area is located in the center of Iran with a warm and desert climate and intense sunlight with a high 
Table 3 Regression coefficients $(\beta(95 \% \mathrm{CI}))$ for associations of creatinine-adjusted concentrations $(\mu \mathrm{g} / \mathrm{g} \mathrm{Cr})$ of benzophenone derivatives in the 1 st and 3rd trimesters with gestational age

\begin{tabular}{|c|c|c|c|c|c|c|}
\hline \multirow[t]{2}{*}{ Metabolite } & \multirow{2}{*}{$\begin{array}{l}\text { All }(N=166) \\
\text { Adjusted } \beta \\
(95 \% \mathrm{CI})\end{array}$} & \multirow[b]{2}{*}{$p$ value } & \multicolumn{2}{|l|}{ Boys $(N=89)$} & \multicolumn{2}{|l|}{ Girls $(N=77)$} \\
\hline & & & $\begin{array}{l}\text { Adjusted } \beta \\
(95 \% \mathrm{CI})\end{array}$ & $p$ value & $\begin{array}{l}\text { Adjusted } \beta \\
(95 \% \mathrm{CI})\end{array}$ & $p$ value \\
\hline \multicolumn{7}{|l|}{ 4-OH-BP } \\
\hline 1st trimester & $\begin{array}{l}0.375 \\
(-0.221,0.972)\end{array}$ & 0.216 & $\begin{array}{l}-0.281 \\
(-1.862,1.301)\end{array}$ & 0.612 & $\begin{array}{l}-0.262 \\
(-2.245,1.721)\end{array}$ & 0.627 \\
\hline 3rd trimester & $\begin{array}{l}-0.199 \\
(-1.922,1.525)\end{array}$ & 0.813 & $\begin{array}{l}-0.153 \\
(-1.187,1.770)\end{array}$ & 0.559 & $\begin{array}{l}-0.19 \\
(-3.246,3.718)\end{array}$ & 0.553 \\
\hline \multicolumn{7}{|l|}{ BP-3 } \\
\hline 1st trimester & $\begin{array}{l}-0.476 \\
(-1.156,0.205)\end{array}$ & 0.169 & $\begin{array}{l}-0.53 \\
(-2.075,1.014)\end{array}$ & 0.355 & $\begin{array}{l}-0.614 \\
(-3.451,3.125)^{*}\end{array}$ & 0.034 \\
\hline 3rd trimester & $\begin{array}{l}0.249 \\
(-1.455,1.952)\end{array}$ & 0.765 & $\begin{array}{l}-0.361 \\
(-6.180,6.982)\end{array}$ & 0.154 & $\begin{array}{l}-0.548 \\
(-1.479,3.910)\end{array}$ & 0.065 \\
\hline \multicolumn{7}{|l|}{ BP-1 } \\
\hline 1st trimester & $\begin{array}{l}0.171 \\
(-1.185,1.412)^{*}\end{array}$ & 0.019 & $\begin{array}{l}-0.547 \\
(-2.064,0.969)\end{array}$ & 0.334 & $\begin{array}{l}-0.612 \\
(-4.688,8.562)^{*}\end{array}$ & 0.034 \\
\hline 3rd trimester & $\begin{array}{l}0.143 \\
(-0.280,0.565)\end{array}$ & 0.506 & $\begin{array}{l}-0.361 \\
(-2.140,2.273)\end{array}$ & 0.154 & $\begin{array}{l}-0.542 \\
(-6.434,9.126)\end{array}$ & 0.069 \\
\hline \multicolumn{7}{|l|}{ BP-8 } \\
\hline 1st trimester & $\begin{array}{l}0.098 \\
(-0.249,0.446)\end{array}$ & 0.576 & $\begin{array}{l}-1.25 \\
(-2.525,0.024)^{*}\end{array}$ & 0.049 & $\begin{array}{l}-0.218 \\
(-1.797,1.362)\end{array}$ & 0.613 \\
\hline 3rd trimester & $\begin{array}{l}-0.605 \\
(-1.820,0.609)\end{array}$ & 0.312 & $\begin{array}{l}-0.169 \\
(-1.473,1.230)\end{array}$ & 0.517 & $\begin{array}{l}0.106 \\
(-0.576,1.519)\end{array}$ & 0.742 \\
\hline
\end{tabular}

${ }^{*} p$ value $<0.05$. Model adjusted for maternal age, pre-pregnancy BMI, weight gain during pregnancy, passive smoking, household monthly income, and education
UV index, which increases the need for sunscreen use, and health care products with high BP-3 (Krause et al. 2012). In such regions, exposure to a high level of BPs can reduce the duration of pregnancy and affect infant birth outcomes. However, according to the results of some studies, in utero exposure to high temperature itself increases the risk of low weight birth (Molina and Saldarriaga 2017). The median concentration of BP-3 and BP-1 showed an increase in the 3rd trimester; however, that for 4-OH-BP was decreased in that term. Studies have shown that 4-OH-BP has a higher transmission rate to the fetus than other metabolites because of its lower molecular weight compared to the others. Therefore, it may be transferred to the fetus more than the other metabolites reducing its concentration in the 3rd trimester in our study (Wang and Kannan 2013; Song et al. 2020).
According to the heat maps in total infants and each sex individually (Figs. 1, 2, and 3), a significant positive correlation was observed between BP-3, BP-1, and 4-OH-BP respectively. BP-1 and 4-OH-BP are phase-I metabolites of BP-3 which have higher estrogenic activity than BP-3 itself. They are hydroxylated benzophenones with 1 more extra hydroxyl group in BP-1, so the main route of BP-3 derivatization in phase-I reactions is hydroxylation (Suzuki et al. 2005). BP-8 showed a very numb correlation with other metabolites; this metabolite also had the lowest concentration among other metabolites and this is probably due to its shorter half-life compared to the other metabolites (Moos et al. 2014). The correlation between BP-3 and its derivatives may be related to the level of exposure to BP-3 and the direct sources of derivatives (Aker et al. 2019; Li et al.
Table 4 Infants' weight characteristics and their classification for gestational age

\begin{tabular}{|c|c|c|c|c|c|c|c|c|c|c|}
\hline \multirow[t]{2}{*}{ Infants } & \multirow[t]{2}{*}{ Mean (g) } & \multirow[t]{2}{*}{ Median (g) } & \multicolumn{2}{|c|}{ Percentiles } & \multicolumn{2}{|c|}{ SGA } & \multicolumn{2}{|c|}{ AGA } & \multicolumn{2}{|c|}{ LGA } \\
\hline & & & 10 & 90 & $N$ & $p(\%)$ & $N$ & $p(\%)$ & $N$ & $p(\%)$ \\
\hline All & 2961.68 & 3070 & 2315 & 3664 & 7 & 4.2 & 130 & 78.3 & 16 & 9.6 \\
\hline Boys & 3086.11 & 3250 & 2565 & 3700 & 8 & 9 & 70 & 78.7 & 10 & 11.2 \\
\hline Girls & 3016.59 & 3050 & 2463 & 3650 & 12 & 16.21 & 55 & 80.9 & 7 & 10.3 \\
\hline
\end{tabular}

$S G A$ small for gestational age, $A G A$ appropriate for gestational age, $L G A$ large for gestational age, $N$ number, $P$ percentage 
Table 5 Gestational age characteristics and classification of delivery terms

\begin{tabular}{|c|c|c|c|c|}
\hline \multicolumn{3}{|c|}{ Gestational age (weeks) } & \multicolumn{2}{|c|}{ Terms of delivery (weeks) } \\
\hline Mean ( SD) & & $38.71 \pm 1.71$ & Preterm $(<37)$ & $N(14)$ \\
\hline Minimum & & 32 & & $p(8.4 \%)$ \\
\hline Maximum & & 43 & Term $(37-42)$ & $N(149)$ \\
\hline \multirow[t]{3}{*}{ Percentiles } & 25 & 38 & & $p(89.75 \%)$ \\
\hline & 50 & 39 & Post-term (>42) & $N(3)$ \\
\hline & 75 & 40 & & $p(1.8 \%)$ \\
\hline
\end{tabular}

2019). In our study, BP-3 was detected in a high concentration. However, in studies detecting a low concentration of BP-3 and its metabolites, no correlation between them has been reported. For example, in China, there was no association between BP-3 and its metabolites due to low levels of them, but in the US population, because of high consumption of sunscreen and cosmetic products resulting in a higher level of exposure to BP-3, a significant positive association between BP-3 and its metabolites has been reported (Wang and Kannan 2013).

Given the importance of gestational age on infants' health, the relationship between EDCs and gestational age has attracted the attention of scientists. In the present study, BP-1 increased gestational age in all infants, but in a specific sex-dependent analysis, BP-3 and BP-1 decreased gestational age in the mothers with female infants. No study was found to evaluate the relationship of BP-1 and 4-OHBP with gestational age. However, in a study, exposure to BP-1 was associated with decreasing birth length in males and birth weight in female infants, but 4-OH-BP has not affected these outcomes (Long et al. 2019). Although the effects of BP-3 on gestational age have not been assessed in many studies, some studies have reported different correlation patterns (Aker et al. 2016, 2018, 2019). There was a good agreement between the findings of our study and a previous study that reported the effect of BP-3 on reducing gestational age (Tang et al. 2013). In that study, BP-3 reduced gestational age -0.45 weeks with a $p$ value of 0.03 in all neonates and more specifically in male neonates. Conversely, in an American study, BP-3 resulted in increasing gestational age in both genders (Aker et al. 2019). Although the estrogenic activity of this metabolite and its binding to estrogen receptors such as $\alpha$ and $\beta$, as well as its association with inflammatory markers, may affect the duration of pregnancy, any differences between the findings of various studies can be attributed to the dose-dependent hormonal effects of this metabolite. So the hormonal activity of BP-3 depends on its level of exposure and received doses (Krause et al. 2012; Aung et al. 2019). Furthermore, it should be noted that apart from exposure to EDCs, preterm birth can be influenced by different factors such as infection, cervical pathology, uterine overdistension, progesterone disorders, vascular alterations, pregnancy stress, allergic phenomena, and perhaps other several unknown factors (Di Renzo et al. 2018).

In this study, we investigated the newborns' weight patterns related to gestational age categorized as SGA (10th P), AGA (10th-90th P), and LGA (90th P). Although in the total infants and independently in boys and girls the majority of infants were in the AGA group followed by the LGA group, weight differences among LGA and SGA were noticeable. This is probably because SGA is a more sensitive parameter and a clear indicator of gestational duration effect on birth weight. Studies demonstrated that maternal exposure to EDCs can increase the risk of SGA and LGA which have adverse health effects for both mother and infant (HerdtLosavio et al. 2008; Messerlian et al. 2018). The results of some cohort studies on pregnant women have shown that high-frequency use of cosmetics increases the risk of SGA up to $80 \%$, but the association with LGA, preterm birth, and

Table 6 Classification of birth outcomes by gestational age at delivery in the total infants

\begin{tabular}{|c|c|c|c|c|c|c|c|}
\hline Week & Birth outcomes & Mean & SD & $95 \% \mathrm{CI}$ & Median & Min & Max \\
\hline \multirow[t]{4}{*}{ Preterm $<37$} & Weight $(\mathrm{g})$ & 2536.25 & 250.767 & (2326.604-2745.896) & 2640 & 2190 & 2840 \\
\hline & Height (cm) & 46.37 & 2.925 & $(43.930-48.820)$ & 46.5 & 41 & 50 \\
\hline & Head circumferences $(\mathrm{cm})$ & 32.62 & 0.443 & $(32.254-32.996)$ & 32.75 & 32 & 33 \\
\hline & Ponderal Index $\left(\mathrm{g} / \mathrm{cm}^{3}\right)$ & 2.56 & 0.321 & $(2.293-2.831)$ & 2.497 & 2.208 & 3.178 \\
\hline \multirow{4}{*}{$\begin{array}{l}\text { Term } \\
37-42\end{array}$} & Weight (g) & 3175.01 & 407.107 & $(3107.475-3242.553)$ & 3170 & 1730 & 4100 \\
\hline & Height (cm) & 50.27 & 2.454 & $(49.864-50.678)$ & 50 & 44 & 57 \\
\hline & Head circumferences $(\mathrm{cm})$ & 34.35 & 3.205 & $(33.817-34.880)$ & 34.9 & 31.6 & 38 \\
\hline & Ponderal Index $\left(\mathrm{g} / \mathrm{cm}^{3}\right)$ & 2.51 & 0.327 & $(2.453-2.561)$ & 2.465 & 1.702 & 3.404 \\
\hline \multirow{4}{*}{$\begin{array}{l}\text { Post term } \\
>42\end{array}$} & Weight $(\mathrm{g})$ & 3000 & 919.239 & - & 3000 & 2350 & 3650 \\
\hline & Height $(\mathrm{cm})$ & 47.50 & 0.707 & $(41.147-53.853)$ & 47.5 & 47 & 48 \\
\hline & Head circumferences $(\mathrm{cm})$ & 35.50 & 0.707 & $(29.147-41.853)$ & 35.5 & 35 & 36 \\
\hline & Ponderal Index $\left(\mathrm{g} / \mathrm{cm}^{3}\right)$ & 2.78 & 0.733 & - & 2.782 & 2.263 & 3.3 \\
\hline
\end{tabular}


low birth weight has not been reported (Halliday-Bell et al. 2009; Quach et al. 2015; Li et al. 2019). In contrast, occupational exposure to these chemicals represented a very significant association with preterm birth, and low birth weight other than SGA (Herdt-Losavio et al. 2008; Kim et al. 2016). The reason for this discrepancy may be due to the length of occupational exposure, and the type and frequency of cosmetics use. Also, in the current study, the newborn boys with a median weight of $3250 \mathrm{~g}$ were heavier than girls with a median weight of $3050 \mathrm{~g}$. Previous studies represented that exposure to BP derivatives during pregnancy resulted in weight loss of newborn females and increased birth weight of newborn males (Gomez et al. 2005; Tang et al. 2013; Long et al. 2019).

Further investigation on the effects of gestational age on birth outcomes showed that the mean weight and length of infants born in less than 37 weeks of pregnancy (preterm birth) were noticeably lower than those of infants born between 37 and 42 weeks (term birth). Head circumference of preterm infants was about $2 \mathrm{~cm}$ smaller than that of term infants, which is an important factor influencing infants' health in the early and later stages of life and increasing the risk of having an abnormal fontanel diameter by 52\% (Woldeyes et al. 2020). Determination of international standards for newborn weight, length, and head circumference according to gestational age showed that the number of preterm birth in Asian pregnant women was higher than that in Europe. Also, the differences among preterm and term newborns' weight, length, and head circumference were so remarkable. Interestingly, the study population was selected from healthy mothers without above-standard exposure to environmental pollutants (Villar et al. 2014). Therefore, pregnant women and their infants in Iran, as an Asian country, have a higher risk of preterm birth. Besides this, exposure to higher levels of environmental pollutants such as BPs increase the health risk of mothers and infants. This requires limitation in the use of BPs containing compounds by vulnerable people and legislation of the uncontrolled application of these compounds in the related manufacturing industry.

In general, very few studies have examined the pregnancy exposure to benzophenone derivatives and their effects on gestational age and birth outcomes. If any, the studies have only focused on BP-3 and the other metabolites have been neglected. Thus, we tried to monitor the four high estrogenic activity derivatives of benzophenones and to assess their correlation with gestational age. The results of this study give basic data of exposure to these potential carcinogen compounds and will be helpful in further healthpollutant interaction studies and risk assessment.

\section{Conclusion}

This study investigated the level of maternal exposure to benzophenones and their association with gestational age for the first time in Iran. All the target compounds were detected in all urine samples. BP-3 and BP-1 in 100\% of the samples, 4-OHBP in $98 \%$ and $82 \%$, and BP- 8 in $95 \%$ and $89 \%$ of the samples were identified in the 1st and 3rd trimester, respectively. BP-3 was the dominant metabolite in the 1st and 3rd trimesters of pregnancy and showed a significant correlation with BP-1 and 4-OH-BP levels in both trimesters. BP-1 represented a significant positive association with gestational age in all infants. However, after stratification by infant sex, the concentrations of BP-3 and BP-1 were associated with decreased gestational age in girls which likely resulted in lower mean birth weight of girls compared to boys. Although the classification of infants' birth outcomes by gestational age displayed that the majority of newborns had appropriate weight for gestational age, preterm birth infants had significantly lower weight, length, and head circumferences than those born in normal terms. Therefore, according to the results, BP derivatives can influence healthy pregnancy and normal growth of the fetus. Given the importance of harmful effects of BPs, notably in the susceptible group, investigation of the wide range of BP derivatives among the different populations should be considered. Also, various sources of BP exposure and their contribution need to be identified in the population. Furthermore, in countries with excessive sources of environmental pollutions, synergist effects of other pollutants alongside emerging environmental pollutants such as BPs on humans should be investigated.

\section{Abbreviations}

BPs: Benzophenones; EDCs: Endocrine-disrupting chemicals; BP-1: 2,4-Dihydroxy benzophenone; BP-3: 2-Hydroxy4-methoxy benzophenone; 4-OH-BP: 4-Hydroxy benzophenone; BP-8: 2,2'-Dihydroxy-4-methoxy benzophenone; PTB: Preterm birth; DLLME: Dispersive liquid-liquid microextraction; GA: Gestational age; SGA: Small-for-gestational age; LGA: Large-for-gestational age; AGA: Appropriate for gestational age; PI: Rohrer's Ponderal Index

Supplementary Information The online version contains supplementary material available at https://doi.org/10.1007/s11356-021-17634-9.

Author contribution The individual contributions of authors to the manuscript are specified as follows:

M. R. S.: supervision, methodology, data curation; M. D.: supervision, data curation; R. K.: supervision, data curation; Y. H.: conceptualization, methodology, supervision, writing — review and editing; H. T.: investigation, methodology, writing-original draft; F. M.: methodology, formal analysis, validation; A. A.: resources, funding acquisition. All authors read and approved the final manuscript. 
Funding This work received financial support from the research deputy of Shiraz University of Medical Sciences via grant No. 20258. The fund was received by Dr. Mohammad Reza Samaei. Also, the main cohort was funded by the Minstry of Health and Medical Education, as the project number 194354 (Research Ethics code: IR.MUI. REC.1394.1.354)

Availability of data and materials All the necessary data generated or analyzed during this study are included in this published article. However, the datasets for statistical analysis are available from the corresponding author on reasonable request.

\section{Declarations}

Ethics approval and consent to participate The protocol and method of the present study were approved by the Persian Cohort Ethics Committee (IR.MUI.REC.1394.1.354).

Consent for publication Not applicable.

Competing interests The authors declare no competing interests.

\section{References}

Aker A, Rios-McConnell RE, Rosario Z et al (2018) Association between Phenols and parabens with gestational age, and the modifying effect of life events during pregnancy. ISEE Conf Abstr 2018. https://doi.org/10.1289/isesisee.2018.p01.2120

Aker AM, Ferguson KK, Rosario ZY et al (2019) The associations between prenatal exposure to triclocarban, phenols and parabens with gestational age and birth weight in northern Puerto Rico. Environ Res 169:41-51. https://doi.org/10.1016/j.envres.2018. 10.030

Aker AM, Watkins DJ, Johns LE et al (2016) Phenols and parabens in relation to reproductive and thyroid hormones in pregnant women. Environ Res 151:30-37. https://doi.org/10.1016/j. envres.2016.07.002

Alamri MS, Qasem AAA, Mohamed AA et al (2021) Food packaging's materials: a food safety perspective. Saudi J Biol Sci 28:4490-4499

Amin MM, Ebrahim K, Poursafa P (2017) Development of a dispersive liquid-liquid microextraction (DLLME) method coupled with GC/MS as a simple and valid method for simultaneous determination of phthalate metabolites in plasma. Int J Environ Anal Chem 97:1362-1377. https://doi.org/10.1080/03067319. 2017.1422497

Anonymous (2020) IARC monographs on the identification of carcinogenic hazards to humans - International Agency for research on cancer. Who

Aung MT, Ferguson KK, Cantonwine DE et al (2019) Associations between maternal plasma measurements of inflammatory markers and urinary levels of phenols and parabens during pregnancy: a repeated measures study. Sci Total Environ 650:11311140. https://doi.org/10.1016/j.scitotenv.2018.08.356

Balázs A, Krifaton C, Orosz I et al (2016) Hormonal activity, cytotoxicity and developmental toxicity of UV filters. Ecotoxicol Environ Saf 131:45-53. https://doi.org/10.1016/j.ecoenv.2016. 04.037

Barone AN, Hayes CE, Kerr JJ, et al (2019) Acute toxicity testing of TiO 2 -based vs. oxybenzone-based sunscreens on clownfish (Amphiprion ocellaris). Environ Sci Pollut Res. https://doi.org/ 10.1007/s11356-019-04769-z
Blencowe H, Cousens S, Chou D et al (2013) Born too soon: the global epidemiology of 15 million preterm births. Reprod Health 10. https://doi.org/10.1186/1742-4755-10-S1-S2

Campo L, Rossella F, Fustinoni S (2008) Development of a gas chromatography/mass spectrometry method to quantify several urinary monohydroxy metabolites of polycyclic aromatic hydrocarbons in occupationally exposed subjects. J Chromatogr B Anal Technol Biomed Life Sci 875:531-540. https://doi.org/10.1016/j.jchromb. 2008.10.017

Chang CH, Wang PW, Liang HW et al (2019) The sex-specific association between maternal paraben exposure and size at birth. Int $\mathrm{J}$ Hyg Environ Health 222:955-964. https://doi.org/10.1016/j.ijheh. 2019.06.004

Chen H, Zhang W, Zhou Y et al (2021) Characteristics of exposure to multiple environmental chemicals among pregnant women in Wuhan. China Sci Total Environ 754:142167. https://doi.org/10. 1016/j.scitotenv.2020.142167

Coughtrie MWH, Burchell B, Leakey JEA, Hume R (1988) The inadequacy of perinatal glucuronidation: immunoblot analysis of the developmental expression of individual UDP-glucuronosyltransferase isoenzymes in rat and human liver microsomes. Mol Pharmacol 34:729-735

Darbre PD (2019) The history of endocrine-disrupting chemicals. Curr Opin Endocr Metab Res 7:26-33

Delgado DM, Barcelo D, Díaz-Cruz S et al (2017) Determination of UV filters in human breast milk using turbulent flow chromatography and babies' daily intake estimation Globaqua View project SEA-on-a-CHIP View project Determination of UV filters in human breast milk using turbulent flow chromatography. Elsevier. https://doi.org/10.1016/j.envres.2017.11.033

Di Renzo GC, Tosto V, Giardina I (2018) The biological basis and prevention of preterm birth. Best Pract Res Clin Obstet Gynaecol 52:13-22

Dodson RE, Boronow KE, Susmann H et al (2020) Consumer behavior and exposure to parabens, bisphenols, triclosan, dichlorophenols, and benzophenone-3: results from a crowdsourced biomonitoring study. Int J Hyg Environ Health 230:113624. https://doi.org/10. 1016/j.ijheh.2020.113624

Fernández MF, Mustieles V, Suárez B et al (2021) Determination of bisphenols, parabens, and benzophenones in placenta by dispersive liquid-liquid microextraction and gas chromatography-tandem mass spectrometry. Chemosphere 274:129707. https://doi. org/10.1016/j.chemosphere.2021.129707

Galal M, Symonds I, Murray H et al (2012) Postterm pregnancy. Facts, Views vis ObGyn 4:175

Gao CJ, Liu LY, Ma WL et al (2015) Benzonphenone-type UV filters in urine of Chinese young adults: concentration, source and exposure. Environ Pollut 203:1-6. https://doi.org/10.1016/j.envpol. 2015.03.036

Ghazipura M, McGowan R, Arslan A, Hossain T (2017) Exposure to benzophenone-3 and reproductive toxicity: a systematic review of human and animal studies. Reprod Toxicol 73:175-183. https:// doi.org/10.1016/j.reprotox.2017.08.015

Gomez E, Pillon A, Fenet H et al (2005) Estrogenic activity of cosmetic components in reporter cell lines: parabens, UV screens, and musks. J Toxicol Environ Heal - Part A 68:239-251. https:// doi.org/10.1080/15287390590895054

Hajizadeh Y, Moradnia M, Kiani Feizabadi G et al (2021) The sexspecific association between maternal urinary paraben levels and offspring size at birth. Environ Sci Pollut Res 28:36029-36038. https://doi.org/10.1007/s11356-021-13175-3

Halliday-Bell JA, Gissler M, Jaakkola JJK (2009) Work as a hairdresser and cosmetologist and adverse pregnancy outcomes. Occup Med (Chic Ill) 59:180-184. https://doi.org/10.1093/occmed/kqp017

Herdt-Losavio ML, Lin S, Druschel CM et al (2008) The risk of having a low birth weight or preterm infant among cosmetologists in New 
York State. Matern Child Health J 13:90-97. https://doi.org/10. 1007/s10995-008-0324-6

Heurung AR, Raju SI, Warshaw EM (2014) Benzophenones. Dermatitis 25:3-10. https://doi.org/10.1097/DER.0000000000000025

Hosseini SN, Mari AM, Jouybari TA, et al (2014) Cosmetic products use intention among Iranian female college students. Int Sci Index 7

Jiang Y, Zhao H, Xia W et al (2019) Prenatal exposure to benzophenones, parabens and triclosan and neurocognitive development at 2 years. Environ Int 126:413-421. https://doi.org/10.1016/j. envint.2019.01.023

Karthikraj R, Kannan K (2018) Human biomonitoring of select ingredients in cosmetics. In: Analysis of Cosmetic Products: Second Edition. Elsevier, pp 387-434

Kawaguchi M, Ito R, Honda $\mathrm{H}$ et al (2009) Miniaturized hollow fiber assisted liquid-phase microextraction and gas chromatographymass spectrometry for determination of benzophenone and derivates in human urine sample. J Chromatogr B Anal Technol Biomed Life Sci 877:298-302. https://doi.org/10.1016/j.jchromb. 2008.12.021

Kerdivel G, Le Guevel R, Habauzit D et al (2013) Estrogenic potency of benzophenone UV filters in breast cancer cells: proliferative and transcriptional activity substantiated by docking analysis. PLoS ONE 8. https://doi.org/10.1371/journal.pone.0060567

Kim D, Kang MY, Choi S et al (2016) Reproductive disorders among cosmetologists and hairdressers: a meta-analysis. Int Arch Occup Environ Health 89:739-753. https://doi.org/10.1007/ s00420-016-1112-z

Kim S, Choi K (2014) Occurrences, toxicities, and ecological risks of benzophenone-3, a common component of organic sunscreen products: a mini-review. Environ Int 70:143-157. https://doi.org/ 10.1016/j.envint.2014.05.015

Krause M, Frederiksen H, Sundberg K et al (2018) Presence of benzophenones commonly used as UV filters and absorbers in paired maternal and fetal samples. Environ Int 110:51-60. https://doi. org/10.1016/j.envint.2017.10.005

Krause M, Klit A, Blomberg Jensen M et al (2012) Sunscreens: are they beneficial for health? An overview of endocrine disrupting properties of UV-filters. Int J Androl 35:424-436

Kunisue T, Chen Z, Buck Louis GM et al (2012) Urinary concentrations of benzophenone-type UV filters in U.S. women and their association with endometriosis. Environ Sci Technol 46:46244632. https://doi.org/10.1021/es204415a

Kunz PY, Galicia HF, Fent K (2006) Comparison of in vitro and in vivo estrogenic activity of UV filters in fish. Toxicol Sci 90:349-361. https://doi.org/10.1093/toxsci/kfj082

Li CC, Chen YT, Lin YT et al (2014) Mesoporous silica aerogel as a drug carrier for the enhancement of the sunscreen ability of benzophenone-3. Colloids Surf B Biointerfaces 115:191-196. https:// doi.org/10.1016/j.colsurfb.2013.11.011

Li H, Zheng J, Wang H et al (2019) Maternal cosmetics use during pregnancy and risks of adverse outcomes: a prospective cohort study. Sci Rep 9. https://doi.org/10.1038/s41598-019-44546-z

Long J, Xia W, Li J et al (2019) Maternal urinary benzophenones and infant birth size: Identifying critical windows of exposure. Chemosphere 219:655-661. https://doi.org/10.1016/j.chemosphere. 2018.11.190

Luu TM, Katz SL, Leeson P et al (2016) Preterm birth: risk factor for early-onset chronic diseases. CMAJ 188:736-740

Mattison DR, Working PK, Blazak WF et al (1990) Criteria for identifying and listing substances known to cause reproductive toxicity under California's proposition 65. Reprod Toxicol 4:163-175. https://doi.org/10.1016/0890-6238(90)90055-Z

Messerlian C, Mustieles V, Minguez-Alarcon L et al (2018) Preconception and prenatal urinary concentrations of phenols and birth size of singleton infants born to mothers and fathers from the
Environment and Reproductive Health (EARTH) study. Environ Int 114:60-68. https://doi.org/10.1016/j.envint.2018.02.017

Mistry P, McInnes EF, Beevers C et al (2021) An evaluation of carcinogenicity predictors from short-term and sub chronic repeat-dose studies of agrochemicals in rats: opportunities to refine and reduce animal use. Toxicol Lett 351:18-27. https://doi.org/10.1016/j.toxlet.2021.08.003

Molina-Molina JM, Escande A, Pillon A et al (2008) Profiling of benzophenone derivatives using fish and human estrogen receptorspecific in vitro bioassays. Toxicol Appl Pharmacol 232:384-395. https://doi.org/10.1016/J.TAAP.2008.07.017

Molina O, Saldarriaga V (2017) The perils of climate change: in utero exposure to temperature variability and birth outcomes in the Andean region. Econ Hum Biol 24:111-124. https://doi.org/10. 1016/j.ehb.2016.11.009

Moos RK, Angerer J, Wittsiepe J et al (2014) Rapid determination of nine parabens and seven other environmental phenols in urine samples of German children and adults. Int J Hyg Environ Health 217:845-853. https://doi.org/10.1016/j.ijheh.2014.06.003

Moradnia M, Attar HM, Heidari Z et al (2021) Prenatal exposure to chromium $(\mathrm{Cr})$ and nickel $(\mathrm{Ni})$ in a sample of Iranian pregnant women: urinary levels and associated socio-demographic and lifestyle factors. Environ Sci Pollut Res 1-10. https://doi.org/10. 1007/s11356-021-15201-w

Mustieles V, Zhang Y, Yland J et al (2020) Maternal and paternal preconception exposure to phenols and preterm birth. Environ Int 137:105523. https://doi.org/10.1016/j.envint.2020.105523

Nakamura N, Inselman AL, White GA et al (2015) Effects of maternal and lactational exposure to 2-hydroxy-4-methoxybenzone on development and reproductive organs in male and female rat offspring. Birth Defects Res Part B - Dev Reprod Toxicol 104:35-51. https://doi.org/10.1002/bdrb.21137

Philippat C, Heude B, Botton J et al (2019) Prenatal exposure to select phthalates and phenols and associations with fetal and placental weight among male births in the EDEN Cohort (France). Environ Health Perspect 127:1-8. https://doi.org/10.1289/EHP3523

Philippat C, Mortamais M, Chevrier C et al (2012) Exposure to phthalates and phenols during pregnancy and offspring size at birth. Environ Health Perspect 120:464-470. https://doi.org/10.1289/ ehp. 1103634

Quach T, Von Behren J, Goldberg D et al (2015) Adverse birth outcomes and maternal complications in licensed cosmetologists and manicurists in California. Int Arch Occup Environ Health 88:823-833. https://doi.org/10.1007/s00420-014-1011-0

Rhodes MC, Bucher JR, Peckham JC et al (2007) Carcinogenesis studies of benzophenone in rats and mice. Food Chem Toxicol 45:843-851. https://doi.org/10.1016/j.fct.2006.11.003

Sakhvidi MJZ, Danaei N, Dadvand P et al (2021) The prospective epidemiological research studies in IrAN (PERSIAN) birth cohort protocol: Rationale, design and methodology. Longit Life Course Stud 12:241-262. https://doi.org/10.1332/175795920X16062 247639874

Santos S, Sol CM, van Zwol-Janssens C et al (2021) Maternal phthalate urine concentrations, fetal growth and adverse birth outcomes. A population-based prospective cohort study. Environ Int 151:106443. https://doi.org/10.1016/j.envint.2021.106443

Smarr MM, Kannan K, Buck Louis GM (2016) Endocrine disrupting chemicals and endometriosis. Fertil Steril 106:959-966

Song S, He Y, Huang Y et al (2020) Occurrence and transfer of benzophenone-type ultraviolet filters from the pregnant women to fetuses. Sci Total Environ 726:138503. https://doi.org/10.1016/j. scitotenv.2020.138503

Suzuki T, Kitamura S, Khota R et al (2005) Estrogenic and antiandrogenic activities of 17 benzophenone derivatives used as UV stabilizers and sunscreens. Toxicol Appl Pharmacol 203:9-17. https://doi.org/10.1016/j.taap.2004.07.005 
Takahashi O, Oishi S (2000) Disposition of orally administered 2,2-bis(4-hydroxyphenyl)propane (bisphenol A) in pregnant rats and the placental transfer to fetuses. Environ Health Perspect 108:931-935. https://doi.org/10.1289/ehp.00108931

Tang R, Chen MJ, Ding GD et al (2013) Associations of prenatal exposure to phenols with birth outcomes. Environ Pollut 178:115-120. https://doi.org/10.1016/j.envpol.2013.03.023

Villar J, Ismail LC, Victora CG et al (2014) International standards for newborn weight, length, and head circumference by gestational age and sex: the Newborn Cross-Sectional Study of the INTERGROWTH-21st Project. Lancet 384:857-868. https://doi. org/10.1016/s0140-6736(14)60932-6

Wai KM, Mar O, Kosaka S et al (2017) Prenatal heavy metal exposure and adverse birth outcomes in Myanmar: a birth-cohort study. Int J Environ Res Public Health 14:1339. https://doi.org/10.3390/ ijerph14111339

Wan Y, Huo W, Xu S et al (2018) Relationship between maternal exposure to bisphenol S and pregnancy duration. Environ Pollut 238:717-724. https://doi.org/10.1016/j.envpol.2018.03.057

Wang L, Kannan K (2013) Characteristic profiles of benzonphenone-3 and its derivatives in urine of children and adults from the United States and China. Environ Sci Technol 47:12532-12538. https:// doi.org/10.1021/es4032908

Wegienka G, Baird DD (2005) A comparison of recalled date of last menstrual period with prospectively recorded dates. J Women's Heal 14:248-252. https://doi.org/10.1089/jwh.2005.14.248
Woldeyes DH, Kiros MD, Abegaz BA, Woya AA (2020) The size of anterior fontanelle and its determinants at birth among neonates in Northern Ethiopia: a cross-sectional study. Pediatr Heal Med Ther 11:477-483. https://doi.org/10.2147/phmt.s283857

Wolff MS, Engel SM, Berkowitz GS et al (2008) Prenatal phenol and phthalate exposures and birth outcomes. Environ Health Perspect 116:1092-1097. https://doi.org/10.1289/ehp.11007

Yang J, Shi S, Xu F, Nie J (2013) Synthesis and photopolymerization kinetics of benzophenone sesamol one-component photoinitiator. Photochem Photobiol Sci 12:323-329. https://doi.org/10.1039/ c2pp25241d

Zhao H, Huo W, Li J et al (2017) Exposure to benzophenones, parabens and triclosan among pregnant women in different trimesters. Sci Total Environ 607-608:578-585. https://doi.org/10.1016/j.scito tenv.2017.07.003

Zhou Z, Lei Y, Wei W et al (2019) Association between prenatal exposure to bisphenol a and birth outcomes: a systematic review with meta-analysis. Medicine (baltimore) 98:e17672. https://doi.org/ 10.1097/MD.0000000000017672

Publisher's Note Springer Nature remains neutral with regard to jurisdictional claims in published maps and institutional affiliations. 